\title{
ANALFABETISMO E NÍVEIS DE LETRAMENTO NO BRASIL: O QUE DIZEM OS CENSOS?
}

\author{
Alceu Ravanello Ferraro*
}

\begin{abstract}
RESUMO: O texto começa discutindo a velha questão da qualidade das estatísticas educacionais e alguns aspectos metodológicos relacionados com a utilização destas na pesquisa em educação. Analisa a seguir o analfabetismo, focalizando: a) a sua emergência como problema político no final do período imperial; b) a evolução do conceito; c) a tendência secular, em números porcentuais e absolutos, desde o primeiro censo em 1872 até o Censo 2000. Por último, com base no Censo 2000, classifica a população em diferentes níveis de letramento.
\end{abstract}

Palavras-chave: Analfabetismo. Níveis de letramento. Censos demográficos. Brasil.

\section{ILLITERACY AND LEVELS OF LITERACY IN BRAZIL: WHAT DO CENSUSES TELL?}

ABSTRACT: This text begins discussing the old issue of the educational statistics quality and some methodological aspects related to their use in educational research. It then analyses illiteracy focusing on: a) its emergency as a political problem at the end of the Brazilian Empire; b) the evolution of this concept; c) the long term trend, both in relative and absolute numbers, from the first 1872 Census to the last one, in 2000. Finally, based on the 2000 Census, it classifies the population according to their different levels of literacy.

Key words: Illiteracy. Literacy levels. Demographic censuses. Brazil.

Professor do Departamento de Educação e do Instituto Ecumênico de Pós-Graduação/IEPG, da Escola Superior de Teologia/Est, São Leopoldo/RS. Professor Titular aposentado da UfRGS. Ex-professor titular da UNISINOS e da UCPEL. Ex-presidente da ANPED, 1989/93. Pesquisador do CNPq. Por determinação judicial, em 1992 foi feita correção no sobrenome, o qual passou de FERRARI para FERRARO.E-mail: aferraro@adufrgs.ufrgs.br 
tema que me foi proposto: "Alfabetização e letramento nos censos" veio acompanhado da definição "Análise dos níveis de analfabetismo e de letramento na população brasileira ao longo dos censos, até o último". Assim posta, a tarefa precisa ser dimensionada não só às possibilidades do autor, mas também ao tempo disponível e aos limites de espaço no dossiê.

Para iniciar, diria que o tema coloca o autor no núcleo da discussão terminológica e conceitual representada por palavras como alfabetização, analfabetismo e letramento, referidos na proposta, e outras como iletrismo, iletrado, alfabetismo, literacia etc. A confusão é tal, que, por exemplo, o Dicionário de Antônimos e Sinônimos, de F. Fernandes (1957), lista como sinônimos de analfabeto os termos ignorante, estúpido, boçal, bronco, sem qualquer referência à condição de não saber ler e escrever, e dá como antônimos simplesmente os termos culto e polido, sem qualquer menção a alfabetizado ou a capacidade de ler e escrever. E claro que "muita água rolou" desde a $11^{\text {a }}$ edição, em 1957, do referido dicionário. A evolução conceitual, especialmente a mais recente, será objeto de outros textos. As questões que não posso deixar de levantar aqui são duas: a primeira é a da comparabilidade, no tempo, das estatísticas censitárias; a segunda é a de saber se e como as estatísticas censitárias podem (cor)responder a conceitos tão polissêmicos e cambiantes como os relacionados com o tema em questão. Esses pontos serão abordados, na medida do possível, quando da utilização dos censos. Inicio abordando, mesmo que de forma muito breve, algumas questôes que poderia denominar preliminares, para enfrentar, a seguir, alguns aspectos que considero mais fundamentais em relação ao tema.

\section{Estatísticas educacionais}

Analisar "níveis de analfabetismo e de letramento na população brasileira ao longo dos censos" implica lidar com estatísticas educacionais. Isso coloca o problema da qualidade (validade e fidedignidade) dessas estatísticas, problema este certamente tão velho quanto as próprias estatísticas, provavelmente mais grave quando se trata de estatísticas sociais, como as da educação. E por demais conhecida a passagem do "Prefácio" da primeira edição de $O$ capital, em que Marx denuncia a miserabilidade da estatística social da Alemanha e do resto do Continente Europeu ocidental, em comparação com a que conhecera na Inglaterra. ${ }^{1}$ Mas nem por isso ele deixa de utilizá-la. E justifica: 
"Ainda assim [ela] levanta o véu o bastante para deixar entrever atrás do mesmo uma cabeça de Medusa”, isto é, as deploráveis condições de exploração e de miséria reinantes no Continente (Marx, 1983, I.I., p. 12-13).

O texto citado de Marx foi originalmente publicado em 1867. Ora, no Brasil, já antes dessa data - antes, portanto, do primeiro censo (1872) -, reclamava-se das estatísticas da educação. É o que relata Lourenço Filho, em sua conferência "Estatística e Educação", proferida em 1940, no Curso de Extensão, instituído pelo recém-criado IBGE (1938): em 1855, em relatório anexo ao relatório do ministro do Império, o então inspetor-geral da Instrução Pública, o conselheiro Eusébio de Queiroz Coutinho Matoso da Câmara, referindo-se às vantagens, para as províncias, do estudo comparativo das realizaçóes no campo da Instrução, chegava à constatação amarga de que, infelizmente, os dados remetidos pelos presidentes não satisfaziam o pensamento da reforma de 1854 . "No nosso país", observava o referido inspetor-geral, "ainda não se compreendeu bem o papel da estatística e poucos sabem das suas condiçôes e exigências" (Câmara, apud Lourenço Filho, 1940, p. 80; grifo na fonte). Nem as sucessivas determinaçôes posteriores do governo foram capazes de fazer cumprir as prescrições do regulamento de 1854 relativamente à organização de uma estatística exata sobre os ramos de ensino no Império. "A queixa deveria atravessar o Império e alcançar a República”, sentenciaria Lourenço Filho quase um século depois (op. cit., p. 81).

$\mathrm{Na}$ realidade, a queixa em relação às estatísticas da educação haveria não só de alcançar a República mas também de atravessá-la em cada um de seus períodos, até o presente. Vou exemplificar. Fletcher (1985, p. 13), diz que a estatística escolar é de validade questionável, porquanto "fornece números irrealistas, os quais tendem a minimizar o problema da repetência”. Fletcher e Ribeiro (1988) colocam em xeque praticamente todas as estatísticas do SEEC/MEC, sustentando que estas produzem superdimensionamento das matrículas, da evasão e da aprovação e subdimensionamento da reprovação e da repetência. Para complicar, estudo recente (Ferraro, Vargas \& Machado, 2001) sugere que o problema pode estar principalmente na má qualidade dos registros escolares, tendo identificado casos relativamente freqüentes de múltipla matrícula, com superdimensionamento, sim, da matrícula e da evasão, porém com subdimensionamento não da reprovação e repetência, como querem Fletcher \& Ribeiro, mas sim da aprovação. 
Cruz dirige dupla crítica a Fletcher \& Ribeiro (1988): primeiro, por sua concepção subjacente de fonte, sob a infundada "alegação de que os dados provêm de declarações da administração das escolas" e não dos registros escolares; segundo, por darem como unidades de análise as escolas (Cruz, 1988, p. 8-9). Essa discussão exige que se recorra a algumas noções gerais da demografia. E este é o próximo ponto a considerar.

2. Estado educacional da população versus movimento do sistema de ensino

A análise dos níveis de analfabetismo e letramento com base nos censos requer se esclareça a especificidade dos censos demográficos nas dimensões do tipo de fonte e da unidade de análise. Sob o aspecto demográfico, as populações humanas podem ser analisadas de dois pontos de vista distintos e complementares: o de seu estado ou situação e o de seu movimento ou dinâmica. ${ }^{2}$ Esses dois tipos de estudos se socorrem de dois tipos básicos de fontes e de estatísticas. Os censos lidam com informações relativas ao estado da população. $\mathrm{Na}$ mesma linha situam-se as diversas pesquisas por amostragem, conduzidas periodicamente pelo IBGE, como as PNADs (Pesquisa Nacional por Amostragem de Domicílio). Já as informaçóes/estatísticas do movimento da população são obtidas principalmente por meio dos registros civis (de nascimentos, mortes, casamentos/separaçóes/ divórcios). Tal divisão não é exclusiva. Os recenseamentos, por exemplo, complementam as informações dos registros sobre o movimento natural da população, além de se constituírem em fonte importante para o estudo dos movimentos migratórios. Há, além disso, outras fontes complementares de estatísticas demográficas do estado da população, como os inquéritos exaustivos sobre conjuntos populacionais reduzidos, as pesquisas nacionais e regionais por amostragem, e os inquéritos retrospectivos por meio de arquivos. De maneira semelhante, os registros também contêm subsídios para se apurar determinadas características da população ou pelo menos de determinados conjuntos populacionais. Por exemplo, dos pais, dos nubentes, dos falecidos. Mas, na perspectiva do presente estudo, interessa firmar a distinção entre os dois tipos básicos de fontes - os censos e os registros civis, e os correspondentes tipos de informação produzida -, estatísticas do estado e estatísticas do movimento da população. 
Há outro aspecto ainda a considerar. As estatísticas do estado da população têm por objeto principalmente unidades estatísticas concretas (indivíduos, domicílios etc.) e permitem descrever o estado da população no momento do levantamento censitário ou amostral, tanto do ponto de vista de sua localização espacial ou distribuição territorial quanto do de sua estrutura ou repartição segundo determinadas características, como sexo, idade, cor, religião, atividade, instrução etc.

Já as estatísticas do movimento da população têm por objeto os eventos demográficos que tiveram lugar durante determinado período de tempo (dia, mês, ano...) e permitem descrever a população do ponto de vista de seu movimento ou dinâmica. É importante distinguir aqui dois tipos de movimentos: o natural, cujos componentes são nascimentos, casamentos e mortes, e o migratório, cujos componentes são a emigração e a imigração. De um modo geral, os registros civis limitamse às informaçóes relacionadas com o movimento natural. Para o estudo do movimento migratório é necessário recorrer a outras fontes, inclusive aos censos demográficos, que costumam classificar a população em migrante e não-migrante. ${ }^{3}$

A distinção entre estado e movimento da população traduz, em última instância, uma classificação geral dos dados demográficos sob o aspecto de seu conteúdo. Conforme se refiram as estatísticas demográficas a unidades estatísticas concretas (indivíduos, domicílios etc.), num dado momento de tempo, ou a unidades estatísticas abstratas, a eventos (nascimentos, mortes etc.), num período determinado de tempo (um ano, por exemplo), obter-se-ão análises do estado ou análises do movimento da população.

O que se acaba de dizer é importante na demografia. E tem tudo a ver com a questão aqui abordada. Na linguagem demográfica, pode-se dizer que os levantamentos censitários e amostrais do IBGE, entre outros, retratam o estado educacional da população, por meio de dados sobre características como alfabetização, freqüência ou não à escola e grau e série freqüentados, anos de estudo e grau concluído. Já os dados do SEEC/MEC, originados dos registros escolares, traduzem o movimento educacional por meio da consideração dos diferentes eventos registrados - matrícula, aprovação, reprovação, repetência, evasão e, como eqüivalente do movimento migratório da população, a transferência entre escolas e até entre turmas de uma mesma escola. Não se trata aqui de decidir quais estatísticas somam mais pontos em termos de validade e fidedignidade: se as censitárias (do IBGE), se as 
originadas dos registros escolares (do SEEC/MEC). Estatísticas são estatísticas. Boas ou ruins, a sua utilização requer sempre critério.

Referi acima algumas restrições levantadas em relação às estatísticas originadas dos registros escolares (só secundariamente, das administraçôes escolares). Convém que se deixe claro que os levantamentos censitários também estão sujeitos a distorçôes. Baste um exemplo. Conforme observado em estudo anterior (Ferrari, 1985), o sub-recenseamento de extensas áreas rurais do país, no censo de 1900, teve como efeito a subestimação do analfabetismo em algumas Unidades da Federação e, conseqüentemente, no Brasil como um todo, com índices de analfabetismo até inferiores aos apurados 20 anos mais tarde pelo recenseamento de 1920. O desconhecimento desse particular tem induzido autores a buscar explicaçōes para a aparente estabilidade e até aumento do analfabetismo entre 1900 e 1920 , o que contraria a dinâmica do fenômeno já estabelecida desde a última década do século $\mathrm{XIX}$, quando na realidade a atenção deveria voltar-se primeiramente para o estudo crítico da fonte. No caso, as falhas de cobertura no censo de 1900 , criteriosamente expostas quando da publicação do censo de 1920 (Brasil, 1920, v. IV, 4a parte). Qualquer tentativa de ajuste dos dados do censo de 1900 deverá levar em conta as informaçôes existentes sobre locais e dimensões do sub-recenseamento. Esta é a razão de não utilizar o censo de 1900 no estudo do analfabetismo.

\section{A especificidade do fenômeno do analfabetismo}

O estudo solicitado requer atenção especial para a perspectiva histórica, cobrindo os quase 130 anos decorridos do primeiro ao último censo realizado no Brasil (de 1872 a 2000). No decurso de um período tão longo, ocorreram várias mudanças conceituais, "dentro" e "fora" dos censos. Essas mudanças suscitam duas questōes principais: a da comparabilidade, entre si, de estatísticas censitárias coletadas em diferentes momentos, especialmente quando definidas por critérios diferentes, e a da viabilidade de utilização dos dados censitários para mensurar conceitos novos, como letramento e iletrismo. Penso que voltar a atenção aqui para a gênese do fenômeno do analfabetismo e a trajetória de sua conceitualização contribuirá para esclarecer este ponto.

Poder-se-ia, à primeira vista, dizer que escolher a perspectiva do analfabetismo, em vez daquela da alfabetização, não muda muito as coisas; que é como escolher cara ou coroa de uma mesma moeda; que é como enfocar o lado problemático de qualquer realidade (o 
analfabetismo, no caso), ou o lado da solução (a alfabetização). Vale, porém, aqui, o alerta de S. Llomovatte: "Hay pocos temas en la problemática social contemporánea de los que se hable tanto e se llegue a tan pocos acuerdos como el analfabetismo y su aparente "solución: la alfabetización"” (Llomovatte, 1989, p. 5). O pouco acordo existente sobre o que se deva entender por analfabetismo e por alfabetização é amplamente reconhecido. $\mathrm{O}$ aspecto mais interessante e provocativo está no fato de a autora ver na alfabetização não mais que a solução "aparente" do analfabetismo. Optar, pois, pela ótica do analfabetismo não se reduz à opção por uma das faces do tema - o seu lado problemático. É necessário atentar para a especificidade do que se denomina analfabetismo.

Tratando da questão da educação republicana no Brasil, V. Paiva faz uma observação importante sobre a questão do analfabetismo. Segundo a autora, era a precariedade quantitativa e qualitativa do nosso sistema de ensino elementar que respondia em grande medida pela amplitude do analfabetismo entre a população brasileira, no momento em que se comemoravam os 100 anos da República. "No entanto" ressalva a autora - "ao longo de grande parte da nossa história essa questão [do analfabetismo] não esteve posta” (Paiva, 1990, p. 9). Que significa isso? O óbvio, ou seja, que ainda não constituía problema o fato de a esmagadora maioria da população brasileira não saber ler e escrever. Ao contrário, era-lhe vedado o acesso à leitura e escrita. A partir de que momento, então, o não saber ler e escrever se tornou um problema? Como observa Paiva, a questão emergiu com a reforma eleitoral de 1882 (Lei Saraiva), a qual, de um lado, derrubou a barreira de renda, mas, de outro, estabeleceu a proibição do voto do analfabeto, critérios estes que foram mantidos, alguns anos mais tarde, pela Constituição republicana de 1891. Observe-se que a questão, como diz Paiva, "se fortalece pela maior circulação de idéias ligadas ao liberalismo e se nutre também de sentimentos patrióticos", suscitados pela divulgação internacional da taxa de analfabetismo segundo o censo de 1890 , que dava para a Brasil a taxa mais alta $(82,63 \%$ para a população de 5 anos e mais) entre os países considerados (Paiva, 1990, p. 9-10), não por qualquer associação que então se pudesse fazer entre alfabetização e trabalho ou produção.

$\mathrm{O}$ analfabetismo, portanto, emergiu no Brasil como uma questão política, não como uma questão econômica. Esta segunda dimensão do problema só seria levantada mais tarde, a partir do segundo pós-guerra, com as teorias do desenvolvimento que dariam 
sustentação teórica e ideológica ao período do Estado keynesiano ou do bem-estar. A Lei Saraiva de 1882, do final do Império, e todas as constituições republicanas anteriores à de 1988 se distinguiram, sob este aspecto, pelo seu caráter discriminatório, rotulador e excludente em relação ao analfabeto. $\mathrm{O}$ analfabetismo constituiu-se na grande vergonha nacional. $\mathrm{O}$ voto foi repetidamente negado aos analfabetos sob o argumento principalmente de sua incapacidade. Os projetos de reforma constitucional nesse ponto questionaram de forma explícita, mas sem resultado, tal incapacidade. Assim, por exemplo, a justificação do Projeto de Emenda Constitucional n. 15, de 1957, do Sr. Armando Falcão:

\begin{abstract}
Sabe-se que cerca de $70 \%$ dos brasileiros são analfabetos (...). Ser analfabeto, entretanto, não significa ser incapaz. $\mathrm{O}$ discernimento não está subordinado à circunstância de saber ler e escrever (...). O analfabeto é um cidadão brasileiro para todos os efeitos. Paga impostos, é convocado para o serviço militar, é chefe de família, pertence a partidos políticos, integra associaçôes de classe, participa de campanhas eleitorais, é proprietário, é agricultor, é industrial. Mas há uma discriminação injusta: não pode ser eleitor (...). O analfabeto tem os ônus da cidadania. Não pode ter, todavia, uma de suas prerrogativas ou faculdades essenciais, o que, mais do que injusto, é iníquo e odioso. (Falcão, in: Rodrigues, 1965, p. 6-7)
\end{abstract}

$\mathrm{Na}$ justificação do Projeto de Emenda Constitucional n. 27, de 1961, Fernando Ferrari e outros argumentam: "Nunca, entretanto, é demais repetir-se que vivemos numa democracia nominal, pois a maior parte da Nação, não alfabetizada, perdida nos campos e nas cidades, não participa das grandes decisões brasileiras". E perguntam: "E como recolherem-se os ecos da 'força social', sem ouvir os 20 milhões de iletrados adultos que povoam o Brasil?” (Ferrari e outros, in: Rodrigues, 1965, p. 9).

Nem teve melhor sorte o tímido Projeto de Emenda à Constituição n. 3, de voto facultativo aos analfabetos, de 1964, do general-presidente $\mathrm{H}$. Castello Branco. Não adiantou rebater a "alegada imaturidade" e a "argumentação de periculosidade de crescimento de um eleitorado de tendência subversiva”. Nem valeu o argumento do deputado Humberto Lucena de que tal receio não procedia, "porquanto o analfabeto, salvo o estabelecido em certas regiōes da agroindústria [referência às 'ligas camponesas' de Julião?], constitui, via de regra, elemento de tendência conservadora" (in: Rodrigues, 1965, p. 11). 
O opúsculo de Rodrigues é de grande interesse também sob o aspecto conceitual. Nas justificaçóes dos projetos de emenda constitucional e nos comentários do autor, analfabeto e iletrado são utilizados como sinônimos. Vejam-se, por exemplo, algumas expressôes utilizadas: "combate à extensão do voto ao iletrado", "contrário à inclusão do iletrado no corpo eleitoral brasileiro", "alegada imaturidade do analfabeto", "o voto do analfabeto", "outorga do direito de voto ao iletrado", "defensores do voto do analfabeto", "alistamento do analfabeto", "contra o voto do iletrado” etc. (Rodrigues, 1965, passim). Já o termo letrado é menos freqüente e parece significar mais do que o conceito censitário "saber ler e escrever". Veja-se, por exemplo, a seguinte passagem: "Outro impasse para outorga do voto ao iletrado, segundo os oponentes à medida, encontra-se no fato de que a sua aprovação engendraria grandes dificuldades para a Justiça Eleitoral, que se veria ante a problemática tarefa de criar expediente diverso do dispensado ao eleitor letrado (...)" (Rodrigues, op. cit., p. 12).

Freire sintetiza de forma admirável as concepções ainda dominantes sobre o analfabetismo:

A concepção, na melhor das hipóteses, ingênua do analfabetismo o encara ora como uma "erva daninha" - daí a expressão corrente: "erradicação do analfabetismo" -, ora como uma "enfermidade" que passa de um a outro, quase por contágio, ora como uma "chaga" deprimente a ser "curada" e cujos índices, estampados nas estatísticas de organismos internacionais, dizem mal dos níveis de "civilização" de certas sociedades. Mais ainda, o analfabetismo aparece também, nesta visão ingênua ou astuta, como a manifestação da "incapacidade" do povo, de sua "pouca inteligência", de sua "proverbial preguiça”. (Freire, 2001, p. 15)

Mas as denominações "erva daninha", "enfermidade", "chaga", "incapacidade" e "preguiça”" estão longe de esgotar a criatividade deformadora e discriminativa em relação ao analfabetismo e aos analfabetos. $\mathrm{O}$ analfabetismo ganha, no Brasil, também uma conotação de marginalidade, periculosidade e risco de subversão. Este último aspecto constitui a vigésima razão invocada por Carneiro contra o voto dos analfabetos: " $20^{a}$ ) a incapacidade do analfabeto não é somente política; ele tende a ser um marginal na sociedade contemporânea e gera novos analfabetos" (Carneiro, 1964, p. 112). Em trabalho mais recente, Carol Daglish discute a relação entre analfabetismo e transgressão nos Estados Unidos. O analfabetismo, segundo a autora, é cada vez mais reconhecido como um "grave problema social", quase a dizer, como "caso de 
polícia". Segundo a autora, a alfabetização tornou-se tão importante na sociedade americana que "ser incapaz de ler e escrever causa profundos sentimentos de isolamento, de ser diferente e inferior, o que com freqüência conduz os analfabetos a juntarem-se a grupo em que essa deficiência é desconhecida e em que eles podem obter algum status. Este é com freqüência um grupo delinqüente" (Daglish, 1983, p. 23).

Em síntese, saber ler e escrever um bilhete simples, segundo a definição censitária, pode significar muito pouco em termos de domínio efetivo da leitura, da escrita e do cálculo. Mas não se lhe pode diminuir o alcance ao mesmo tempo educacional, social e político. Com efeito, a alfabetização, mesmo nesse sentido restrito, representa, de um lado, a libertação das múltiplas formas de preconceito, rotulação e estigmatização ainda vigentes em relação ao analfabeto, como se viu acima, e, de outro, a superação da barreira e a efetivação do primeiro passo no caminho da alfabetização e do letramento. É justamente na primeira série da educação fundamental que se produzem com maior freqüência a retenção e a defasagem na relação série/idade no processo de escolarização.

\section{Evolução conceitual e parâmetros da alfabetização e do analfabe- tismo}

As dificuldades de ordem conceitual no tratamento do problema da relação com a palavra e a cultura escritas podem muito bem ser ilustradas com o título da obra de Carlo Cipolla: Literacy and development in the West (1970), impropriamente vertida para o espanhol sob o título Educación y desarrollo in Occidente (1970). Como em português, também na língua espanhola não havia correspondente para o termo inglês literacy, lacuna esta só muito recentemente preenchida pelos neologismos literacia, em Portugal, e letramento, no Brasil (Tfouni, 1988; Soares, 1998).

Mas vamos reconstruir brevemente a "trajetória" conceitual naquilo que aqui mais interessa. A assinatura do próprio nome em documentos tem sido utilizada historicamente como indicativa de alfabetização, e a assinatura com uma cruz, como indicativa de analfabetismo. Há, no caso, uma verificação de fatos: assinatura do próprio nome ou aposição de uma cruz em lugar do nome. Goody esclarece o significado da assinatura: “(...) o equivalente do juramento oral é a confissão assinada. A assinatura torna-se efetivamente um substituto para a pessoa, pelo menos no fundo de cheques". E 
acrescenta: "Mas não se limita a ser um cartão de identidade, tão individual como a impressão do dedo ou da mão, sendo também a afirmação de verdade e de consentimento" (Goody, 1987, p. 173). O estudo de Cipolla (1970) e a obra já clássica dirigida por Furet e Ozouf (1977) servem-se tanto deste conceito e parâmetro como da definição censitária saber ler e escrever, que esteve em vigor desde os primeiros censos demográficos no Ocidente até as primeiras décadas do século XX. Por influência da Unesco, no Brasil, no Censo Demográfico 1950 o conceito passou a ter o seguinte teor: "Como sabendo ler e escrever entendem-se as pessoas capazes de ler e escrever um bilhete simples, em um idioma qualquer, não sendo assim consideradas aquelas que apenas assinassem o próprio nome". Com pequenas variações de redação, esta definição esteve em vigor até o Censo 2000, onde se lê: "Considerou-se como alfabetizada a pessoa capaz de ler e escrever um bilhete simples no idioma que conhecesse. Aquela que aprendeu a ler e escrever, mas esqueceu, e a que apenas assinava o próprio nome foram consideradas analfabetas" (IBGE, 2000). A observação no Censo 1950 de que "Critério idêntico vigorou em relação ao Censo Demográfico 1940” (IBGE, 1950) confunde. Aliás, em estudo organizado e publicado pelo próprio IBGE, no texto "A alfabetização da população no Brasil segundo o sexo, a idade e a cor", lê-se exatamente o contrário:

Cumpre advertir que no censo de 1950 a capacidade de ler e escrever do recenseado foi determinada com critérios mais rigorosos do que no ano de 1940. Por esta diversidade de critério foram prejudicados, embora não inutilizados, os cálculos sobre a variação da alfabetização entre as duas épocas. As quotas de alfabetização de 1940 deveriam ser reduzidas, especialmente nas primeiras idades consideradas, para ficarem corretamente comparáveis com as de 1950. (IBGE, 1961, p. 391, nota 2)

A propósito, impõem-se duas observações. Primeiro, houve mudança de conceito do censo de 1940 para o de 1950. Também a Argentina, por exemplo, adequou-se à nova orientação da UNESCO no censo de 1960, definição esta não aplicada no censo de 1947 (Argentina, 1966). Segundo, a julgar pela própria dinâmica do analfabetismo, como se verá adiante, não há evidências de que tal mudança conceitual tenha comprometido a comparabilidade dos dois censos no nível aventado pelo estudo acima referido.

Há outro aspecto a lembrar. Para o que aqui interessa, segundo os censos é computada como alfabetizada não a pessoa que saiba, mas a que tenha declarado saber ler e escrever (a partir de 1950, que tenha 
declarado saber ler e escrever um bilhete simples no idioma que conhecesse). É computada como analfabeta a que tenha declarado não saber.

Certamente, saber ler e escrever é mais do que assinar o nome. Alguém pode saber assinar o nome e não saber ler e escrever. Mas isso não é tudo. Valeria a declaração mais do que a assinatura? A questão é relevante, especialmente se, como se viu acima, a condição de analfabeto vem carregada de preconceitos, discriminação e estigmatização. Mas o que se disse acima sugere outra questão intrigante: Em que medida a passagem da definiçâa saber ler e escrever para saber ler e escrever um bilhete simples representa a adoção de critério mais rigoroso? Que repercussão essa mudança teve nos censos? É o que se tentará ver adiante.

Até aqui me detive nos conceitos censitários de analfabetismo e alfabetização. Por ora é suficiente. Para as múltiplas tentativas de redefinição do fenômeno encetadas pela UNESCO, pode-se consultar o texto de Perrotta (1985).

\section{Tendência do analfabetismo: aspectos metodológicos}

Passarei agora a focalizar a tendência secular do analfabetismo no Brasil com base no critério censitário, isto é, na declaração de incapacidade de ler e escrever (de ler e escrever um bilhete simples, a partir de 1950). Apesar das múltiplas limitações que lhe são atribuídas, penso que o critério censitário deva ser preservado pelos seguintes motivos: 1) ele constitui a única informação do estado educacional da população disponível nos censos anteriores a 1940;2) o analfabetismo em sua forma extrema, como a detectada pelo censo, é indicativo de um fenômeno real, com múltiplas conotações de preconceito, rotulação, discriminação e estigmatização, constituindo a forma extrema de exclusão educacional; 3) o analfabetismo assim definido ainda persiste no Brasil.

Em estudo anterior (Ferrari, 1985) analisei a tendência secular do analfabetismo no Brasil do Censo 1872 ao Censo 1980. Estendo agora a análise até os censos de 1991 e 2000. Por razōes de tempo e espaço, limito-me ao país como um todo, sem atenção especial para as desigualdades regionais. Deixo de considerar o Censo 1900 pela razão já apontada acima: o subdimensionamento do analfabetismo em algumas Unidades da Federação e no conjunto do país, em decorrência de sub-recenseamento de extensas área rurais. ${ }^{4}$ Para os censos de 1872 e 1890, o melhor indicador que se pode obter é para a população de 5 
anos ou mais. E isso por meio de um artifício: a subtração da população de 0 e 4 anos da população recenseada como analfabeta, uma vez que os referidos censos consideraram, para efeito de analfabetismo, a população total. A fórmula é simples: \% de analfabetos entre a população de 5 anos ou mais = (população total analfabeta de 0 anos ou mais) - x 100 (população total) - (0 - 4 anos). Para efeito de comparaçõos internacionais, a UNESCO tem privilegiado taxas de alfabetização/analfabetismo para a população de 15 anos ou mais. No Brasil, esse indicador pode ser construído a partir do Censo 1920. Os países latino-americanos têm, de um modo geral, preferido considerar a população de 10 anos ou mais para cômputo do analfabetismo, indicador este disponível, no Brasil, a partir de 1940.

6. Queda secular da taxa de analfabetismo e avanço secular do número de analfabetos

Passa-se agora à análise da tendência do analfabetismo. A simples observação da tabela 1 e dos gráficos 1 e 2 evidencia a simultaneidade, por mais de um século, de duas dinâmicas opostas do analfabetismo: a queda secular da taxa porcentual de analfabetismo e o aumento, também secular, do número absoluto de analfabetos.

Um olhar atento para as taxas de analfabetismo constantes na tabela 1 e no gráfico 1 permite a seguinte periodização da trajetória da taxa de analfabetismo a partir de 1872 para a população de 5 anos ou mais:

1) taxas extremamente elevadas e estáveis (em torno de 82,5\%) no período que vai do primeiro ao segundo censo (1872 a 1890);

2) queda em ritmo mais ou menos constante no período de 1890 a 1950 , com redução da taxa de analfabetismo para $57,2 \%$ no Censo 1950;

3) intensificação da queda no curto período de 1950 a 1960, com redução da taxa para $46,7 \%$;

4) desaceleração no ritmo de queda da taxa de analfabetismo a partir de 1970 até 2000 , com taxas caindo sucessivamente para 38,7\%, $31,9 \%, 24,2 \%$ e $16,7 \%$, sempre para a população de 5 anos ou mais.

Neste último período o ritmo de queda praticamente retorna ao que fora no período de 1890 a 1950, não se evidenciando qualquer 


\section{Tabela 1}

Evolução do número de analfabetos e da taxa de analfabetismo entre a população de 5 anos ou mais, 10 anos ou mais e 15 anos ou mais, segundo os censos demográficos. Brasil, 1872 a 2000.

\begin{tabular}{|c|c|c|c|}
\hline \multirow{3}{*}{$\begin{array}{l}\text { Ano do } \\
\text { Censo }\end{array}$} & \multicolumn{3}{|c|}{ População } \\
\hline & \multirow[b]{2}{*}{ Total } & \multicolumn{2}{|c|}{ Não alfabetizada } \\
\hline & & $\mathrm{N}^{\mathrm{o}}$ & $\%$ \\
\hline \multicolumn{4}{|c|}{ a) População de 5 anos e mais } \\
\hline 1872 & 8.854 .774 & 7.290 .293 & 82,3 \\
\hline 1890 & 12.212 .125 & 10.091 .566 & 82,6 \\
\hline 1920 & 26.042 .442 & 18.549 .085 & 71,2 \\
\hline 1940 & 34.796 .665 & 21.295 .490 & 61,2 \\
\hline 1950 & 43.573 .517 & 24.907 .696 & 57,2 \\
\hline 1960 & 58.997 .981 & 27.578 .971 & 46,7 \\
\hline 1970 & 79.327 .231 & 30.718 .597 & 38,7 \\
\hline 1980 & 102.579 .006 & 32.731 .347 & 31,9 \\
\hline 1991 & 130.283 .402 & 31.580 .488 & 24,2 \\
\hline 2000 & 153.423 .442 & 25.665 .393 & 16,7 \\
\hline \multicolumn{4}{|c|}{ b) População de 10 anos ou mais } \\
\hline 1940 & 29.037 .849 & 16.452 .832 & 56,7 \\
\hline 1950 & 36.557 .990 & 18.812 .419 & 51,5 \\
\hline 1960 & 48.839 .558 & 19.378 .801 & 39,7 \\
\hline 1970 & 65.867 .723 & 21.638 .913 & 32,9 \\
\hline 1980 & 87.805 .265 & 22.393 .295 & 25,5 \\
\hline 1991 & 112.860 .254 & 21.330 .966 & 18,9 \\
\hline 2000 & 136.881 .115 & 17.552 .762 & 12,8 \\
\hline \multicolumn{4}{|c|}{ c) População de 15 anos ou mais } \\
\hline 1920 & 17.557 .282 & 11.401 .715 & 64,9 \\
\hline 1940 & 23.709 .769 & 13.242 .172 & 55,9 \\
\hline 1950 & 30.249 .423 & 15.272 .632 & 50,5 \\
\hline 1960 & 40.278 .602 & 15.964 .852 & 39,6 \\
\hline 1970 & 54.008 .604 & 18.146 .977 & 33,6 \\
\hline 1980 & 73.542 .003 & 18.716 .847 & 25,5 \\
\hline 1991 & 95.810 .615 & 18.587 .446 & 19,4 \\
\hline 2000 & 119.533 .048 & 16.294 .889 & 13,6 \\
\hline
\end{tabular}

Fontes: Para 1872, 1890 e 1920, ver: Brasil, Recenseamento Geral do Brasil 1920 , v. IV, $4^{\text {a }}$ parte - População, e IBGE, Censo 1940, os quais reproduzem os dados dos censos anteriores. Para os demais censos, ver: IBGE, Censo demográfico, $1940,1950,1960,1970,1980,1991,2000$. O Censo de 1900 não foi considerado em razão das distorsões sobre o analfabetismo resultantes do subrecenseamento de extensas áreas ruais em alguns estados. Sobre isto ver: Brasil, Receseamento Geral 1920, e Ferrari (1985). 


\section{Gráfico 1}

Tendência secular das taxas de analfabetismo entre a população de 5 anos ou mais, 10 anos ou mais e 15 anos ou mais, segundo os censos demográficos. Brasil, 1872 a 2000.

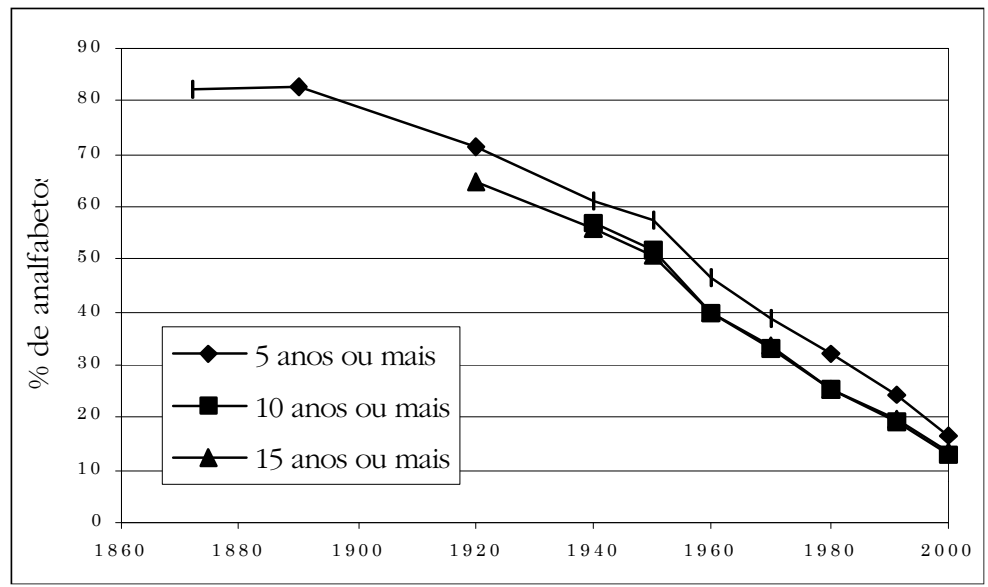

Fontes: Tabela 1.

\section{Gráfico 2}

Tendência secular do número de analfabetos entre a população de 5 anos ou mais, 10 anos ou mais e 15 anos ou mais, segundo os censos demográficos. Brasil, 1872 a 2000.

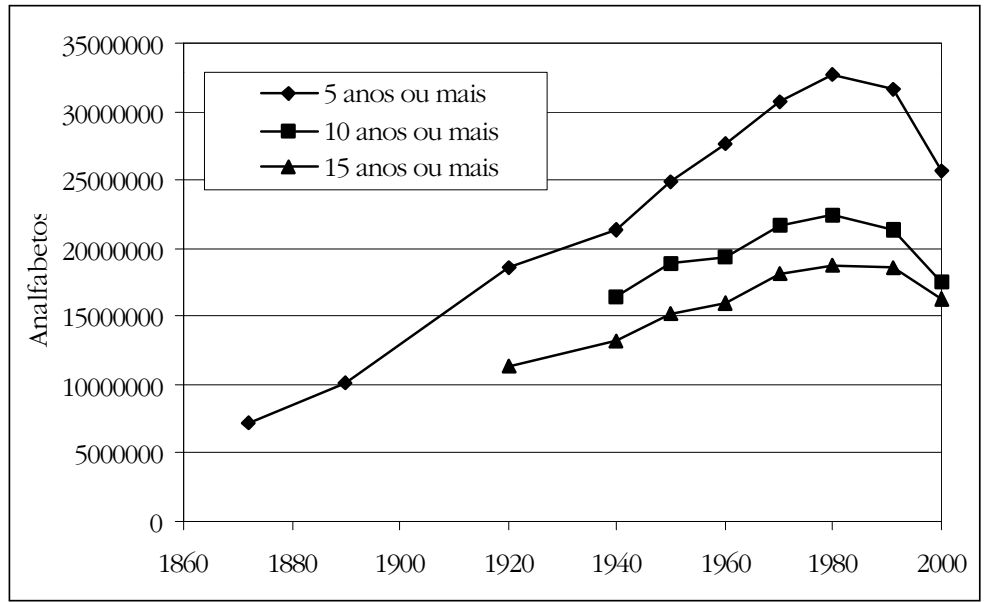

Fontes: Tabela 1.

Educ. Soc., Campinas, vol. 23, n. 81, p. 21-47, dez. 2002

Disponível em <http://www.cedes.unicamp.br> 
impacto maior de iniciativas como MOBRAL, Fundação Educar, Educação para Todos e das leis, dos planos e dos muitos discursos... no período. Quase a dizer que se trata de tendência inexorável, a qual, querendo ou não querendo o Poder público, seguirá imperturbável o seu curso.

É possível que o pequeno arrebite na curva, verificado em 1950, tenha a ver com a mudança de definição de alfabetizado no Censo 1950, que passou de "ler e escrever", para "ler e escrever um bilhete simples". De qualquer forma, o efeito da mudança é quase imperceptível dentro da trajetória secular da taxa de analfabetismo. Além do mais, foi justamente na década seguinte (1950/60) que se verificou a maior queda porcentual verificada desde o primeiro até o último censo. $\mathrm{Na}$ realidade, descontadas as pequenas "perturbaçôes" de tendência verificadas nas décadas de 1940/50 e 1950/60, teríamos um movimento de queda muito regular, numa curva em leve descenso em todo o período de 1890 a 2000.

As taxas de analfabetismo para as populações de 15 anos ou mais (a partir de 1920) e 10 anos ou mais (a partir de 1940) praticamente coincidem entre si e seguem a mesma trajetória de longo prazo da taxa de analfabetismo apurada entre a população de 5 anos ou mais, porém com taxas mais baixas em aproximadamente 5 a 5,5 pontos porcentuais. A regularidade é tal que se pode facilmente imaginar que as taxas para 15 anos ou mais e 10 anos ou mais nos dois primeiros censos deveriam girar em torno de $77 \%$ para o Brasil.

A aproximação da taxa de analfabetismo para 5 anos ou mais em relação às taxas para 10 anos ou mais e 15 anos ou mais no Censo 2000 deve estar indicando avanço na alfabetização infantil.

Se, de um lado, é visível, no gráfico 1, a queda progressiva da taxa de analfabetismo no Brasil a partir da década de 1890 até 2000, não é menos visível, no gráfico 2 , o aumento continuado do número absoluto de analfabetos por mais de 100 anos, a saber, em todo o período que vai de 1872 até 1980 . Com efeito, nesse período, o número de analfabetos multiplicou-se por 4,5 vezes na população de 5 anos ou mais, passando de 7,3 milhões em 1872 para 32,7 milhões em 1980, quando atinge o número máximo. O gráfico 2 revela uma quase reta ascendente, bastante regular. Somente o censo de 1991 haveria de anunciar uma leve inversão de tendência (de queda, agora), que se iria acentuar na última década do século findo.

Para os períodos em que se dispõe de dados, as populações de 15 anos ou mais e 10 anos ou mais apresentam tendências na mesma direção 
da população de 5 anos ou mais, isto é, de aumento até 1980 e de queda a partir daí. Nos 60 anos que vão de 1920 a 1980, o número de analfabetos multiplicou-se por 1,64 entre as pessoas de 15 anos ou mais (de 11,4 para 18,7 milhões, respectivamente), e nos 40 anos que vão de 1940 a 1980, o número de analfabetos sofreu um aumento da ordem de 1,36 vezes entre as pessoas de 10 anos ou mais (de 16,5 para 22,4 milhões). Também aqui a mudança de tendência - de aumento para queda no número absoluto de analfabetos - só acontece a partir da década de 1980 e só se torna pela primeira vez visível no Censo 1991.

\section{Alfabetização e letramento a partir dos censos}

Expus acima as razóes para se manter o critério "capacidade de ler e escrever um bilhete simples" utilizado nos censos brasileiros para classificação da população em alfabetizada e analfabeta. Baseou-se nesse critério a análise que acabo de fazer da tendência do analfabetismo no Brasil. Sempre evitei o uso dos termos "alfabetização funcional" e "analfabetismo funcional”. Sua adoção acarretaria, entre outras dificuldades, a criação de tantos critérios, ou medidas de analfabetismo funcional e de alfabetização funcional, quantos, por exemplo, os níveis de desenvolvimento dos diferentes países ou regiôes, assim como os níveis de demanda de leitura e escrita postos pelas mais diversas profissões. Não é o caso de me alongar na discussão a respeito. Fica o registro.

Em estudo recente propus a classificação da população em quatro níveis de alfabetização, construídos com base na informação censitária "anos de estudo" concluídos com aprovação. Trata-se de projeto desenvolvido com apoio do CNPq, no período de 1997/99 (Ferraro, 1999a e 1999b). O objetivo, então, era outro: consistia em avaliar o número e a porcentagem de crianças, adolescentes e jovens que tivessem conseguido atingir cada um dos níveis dentro da idade "própria", isto é, que já tivessem concluído a $1^{\mathrm{a}}$, a $4^{\mathrm{a}}$ e a $8^{\mathrm{a}}$ séries do ensino fundamental e a última da educação média, respectivamente aos 8 anos, aos 11 anos, aos 15 anos e aos 18 anos de idade. $O$ objetivo aqui é outro: é determinar o número e o porcentual de brasileiros das diferentes idades que atingiram cada um dos diferentes níveis de escolaridade, medidos em termos de anos de estudo concluídos.

$\mathrm{O}$ resultado do presente experimento de categorização pode ser observado nas tabelas 2 e 3, que consideram a população de 10 anos ou mais, com destaque também para a de 15 anos ou mais. A primeira categoria que emerge dessa construção é formada pela soma dos (que se 
declararam) "sem instrução" ou com "menos de 1 ano de estudo" concluído, ou seja, que, mesmo tendo freqüentado escola, não haviam concluído sequer a $1^{\text {a }}$ série do ensino elementar, $1^{\circ}$ grau ou fundamental. Essa definição dá, entre as pessoas de 10 anos ou mais, no ano de 1996, um total de 16,9 milhões de pessoas sem instrução ou com menos de 1 ano de estudo. Este número (16,9 milhões em 1996), que resulta da aplicação do conceito/critério sem instrução + menos de 1 ano de estudo, fica muito próximo dos quase 17,6 milhões de analfabetos computados por meio do critério ler e escrever um bilhete simples no Censo 2000, em ambos os casos entre a população de 10 anos ou mais (tabelas 1 e 2). A diferença pode até inverter-se, se levados em conta o elevado número de pessoas com anos de estudo não declarados (1 milhão) e o aumento da população de 1996 para 2000.

Vista a coisa de outro ângulo, pode-se considerar que todas as pessoas que apresentem pelo menos 1 ano de estudo concluído compóem um total próximo do número de alfabetizados apurado pelo critério ler e escrever um bilhete simples. A hipótese é que, com base no critério anos de estudo concluídos (pelo menos 1 ano), pode-se construir alguns níveis significativos de letramento, neologismo criado recentemente no Brasil, que traduz o termo inglês literacy (literacia em Portugal) e que significa "o estado ou condição que assume aquele que aprende a ler e escrever", como diz Magda Soares (1998, p. 17). E a autora esclarece: "Letramento é, pois, o resultado da ação de ensinar ou de aprender a ler e escrever: o estado ou a condição que adquire um grupo social ou um indivíduo como conseqüência de ter-se apropriado da escrita” (op. cit., p. 18). A questão toda está em definir onde fazer os cortes na escala de anos de estudo. A idéia original prevê o estabelecimento de quatro níveis de letramento, com corte na $1^{a}$, na $4^{a}$ e na $8^{a}$ séries da educação fundamental e na $3^{\text {a }}$ (última) do ensino médio. Em virtude da forma de agrupamento dos anos de estudo na Contagem 1996 (ela agrupa todas as séries da educação média, não permitindo destacar os que concluíram o grau), o experimento aqui desenvolvido se limita aos três primeiros níveis.

\section{Níveis de letramento com base na informação censitária anos de estudo}

O nível 1 de letramento compreende todos aqueles que informaram ter um a três anos de estudo concluídos. De um lado, ele sinaliza a ultrapassagem da barreira que se interpóe entre o analfabetismo na sua forma mais cabal e o que se poderia chamar de mínimo dos mínimos em 
termos de alfabetização e letramento, que coincidiria aproximadamente tanto com a conclusão da $1^{\text {a }}$ série fundamental (um ano de estudo) quanto com o conceito "ler e escrever um bilhete simples". De outro lado, significa o não-alcance ainda do nível 2. Mesmo que o nível 1 não assegure a competência mínima para operar ou praticar no cotidiano, com alguma desenvoltura, a leitura, a escrita e o cálculo, nem seja suficiente para tornar improvável a reversão ao analfabetismo, certamente representa um salto importante no que tange à educação e aos direitos sociais em geral, porquanto permite ao menos livrar-se dos preconceitos e da estigmatização de que sempre têm sido alvo os analfabetos no Brasil, como se viu antes.

Esse critério coloca no nível 1 de letramento (no nível do mínimo dos mínimos) quase 26,9 milhões de brasileiros de 10 anos ou mais, o equivalente a $21,6 \%$ do total (tabelas 2 e 3 ). Se utilizado um critério mais rigoroso de alfabetização, como sugerem alguns autores (por exemplo: Llomovate, 1989) e como tenho utilizado em diferentes trabalhos (Ferraro(i), 1985, 1987, 1999a e 1999b...), todo esse grupo engrossaria a estatística da população analfabeta, a qual somaria, para o ano de 1996, 16,9 + 26,9 milhões. No entanto, reavaliando hoje esse procedimento, penso que esta não seja a melhor forma de iluminar a questão, inclusive para efeito de políticas de educação e de práxis educativa. Assim se estaria, talvez, desqualificando aquilo que constitui o momento inicial e o primeiro passo, decisivo, no processo de escolarização e alfabetização. Penso que seria preferível considerar um a três anos de estudo como o primeiro nível de letramento.

O nível 2 de letramento compreende todos aqueles que tenham concluído pelo menos a $4^{\mathrm{a}}$ série e que não tenham ido além da $7^{\mathrm{a}}$ série do fundamental. A definição desse nível se apóia na suposição de que a conclusão da $4^{\mathrm{a}}$ série representa o alcance do domínio mínimo da leitura, da escrita e do cálculo, que permite à pessoa valer-se no dia-adia de tais técnicas e conhecimentos, e a partir do qual se tornaria improvável o retorno ao analfabetismo. Esse nível coincidiria com o antigo primário. Llomovate (1989, p. 9), em estudo sobre o analfabetismo na Argentina, sugere que esse ponto estaria em quatro ou cinco anos de estudo. De minha parte, venho de longa data utilizando e sugerindo, para tal fim, o uso do critério quatro anos de estudo. Esse nível foi também denominado "alfabetização funcional", como o fazem, por exemplo, Carvalho, Kappel e Alves (In: IBGE, 1995, p. 284). De minha parte direi que o primeiro nível significa livrar-se do estigma, ao passo que este segundo atesta a aquisição da capacidade 


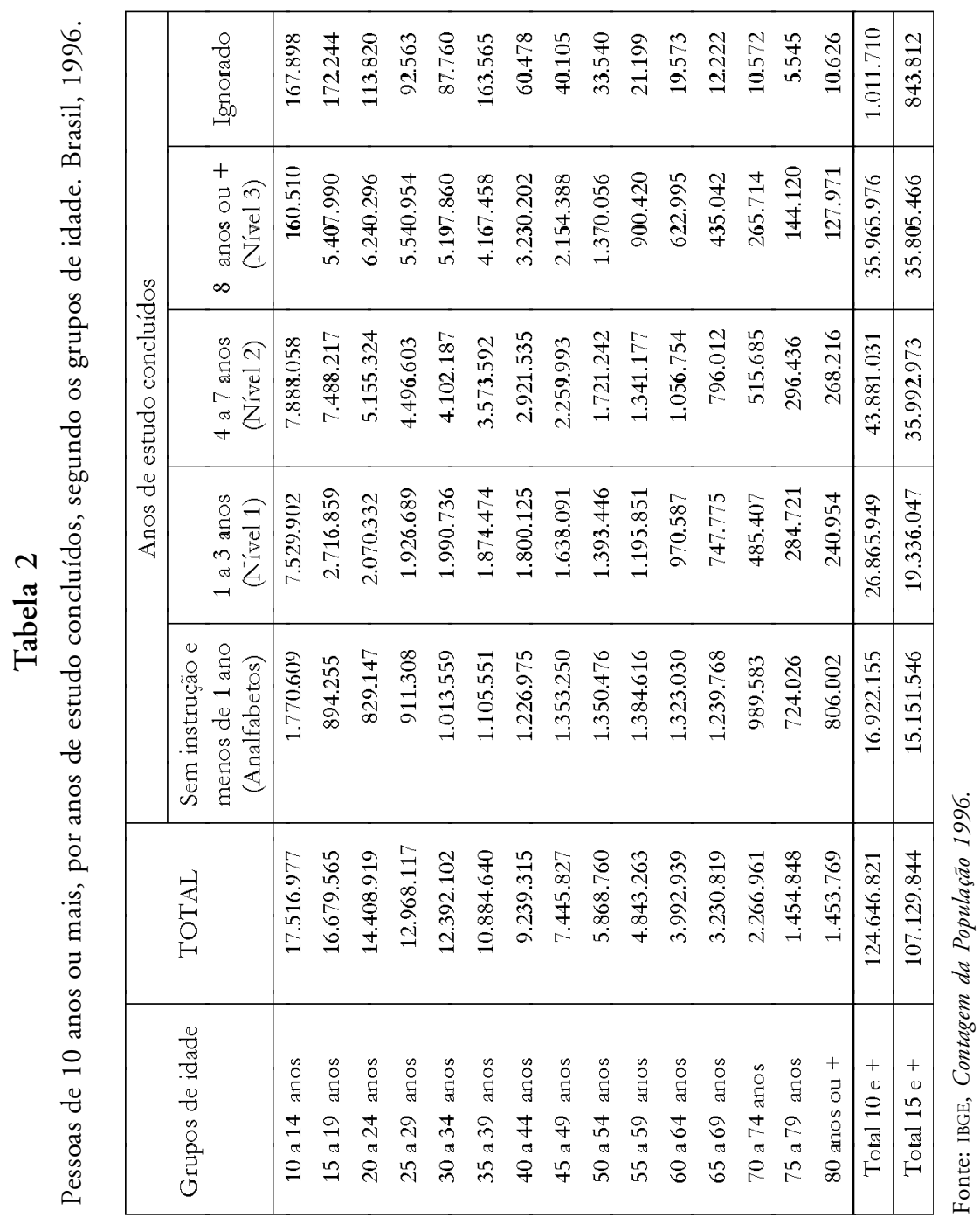




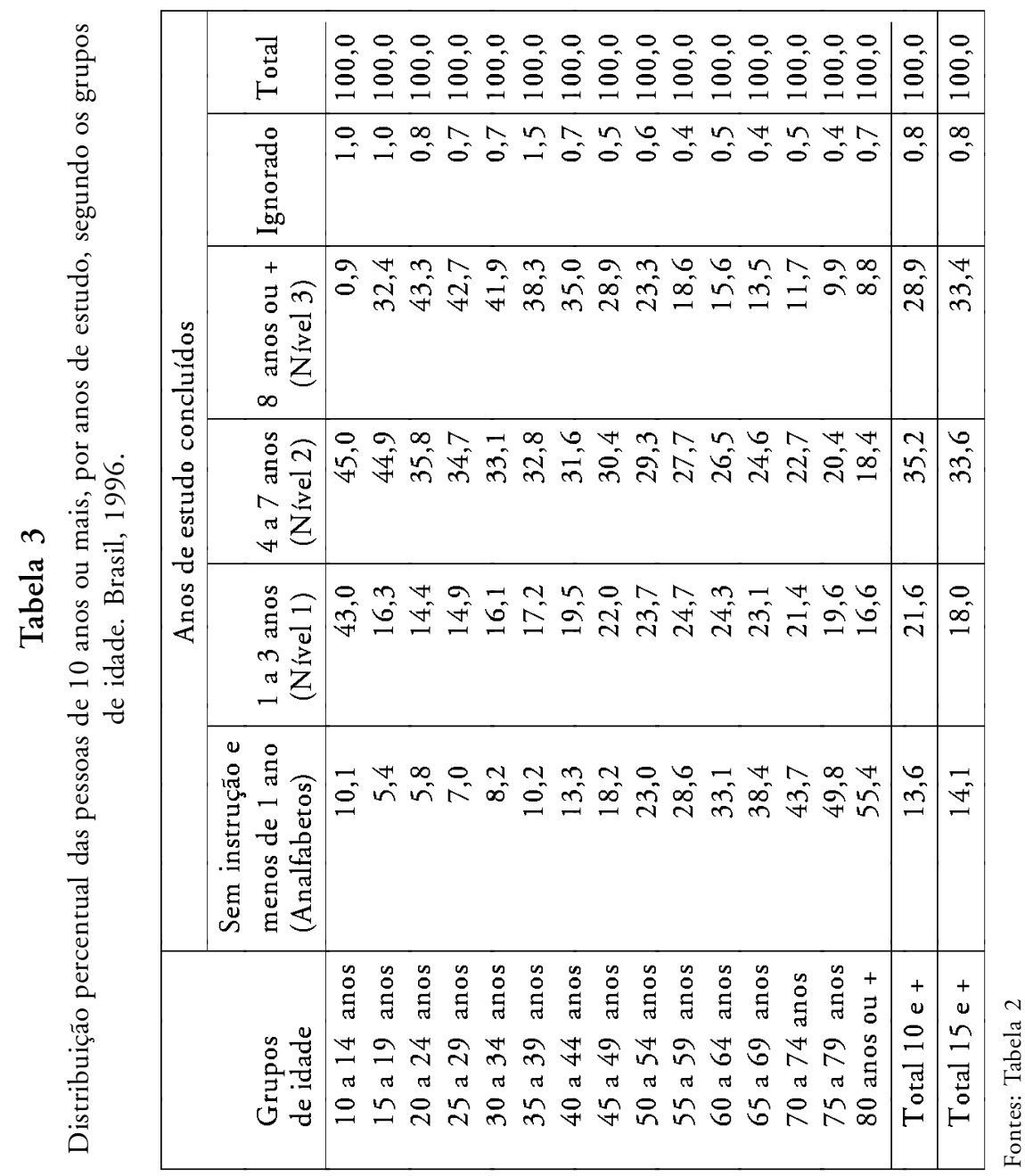

Educ. Soc., Campinas, vol. 23, n. 81, p. 21-47, dez. 2002

Disponível em <http://www.cedes.unicamp.br> 
mínima de operação em sentido mais amplo e universal que o contido na expressão "alfabetização funcional”, fortemente colada ao mercado de trabalho. Por isso, para evitar os já aludidos problemas que acompanham essa noção, opto por denominá-lo nível do minimo operacional, entendido como a competência mínima para operar, na vida cotidiana, com a leitura, a escrita e o cálculo, mesmo antes do ingresso no mercado de trabalho e independentemente da função que cada um(a) nele venha a exercer.

Situam-se nesse segundo nível de letramento 43,9 milhões de pessoas de 10 anos ou mais, representando 35,2\% do total. Ainda que se considere apenas a população de 15 anos ou mais, mesmo assim esse número permanece altíssimo: 36 milhões, o que equivale a 33,6\% do total (tabelas 2 e 3).

Como antecipei acima, na idéia original o nível 3 de letramento compreenderia todos aqueles que tivessem oito anos de estudo concluídos, isto é, fundamental completo, mais médio incompleto (nove a dez anos de estudo). Ele significaria a realização do mínimo constitucional, mas não ainda a conclusão da educação básica, que por sua vez constituiria o nível 4, compreendendo todos os que tivessem concluído com sucesso o nível médio (11 anos de estudo ou mais). Infelizmente, a forma como foram agrupados os anos de estudo não permite esse desdobramento nos níveis 3 e 4 . A opção é reunir tudo, a partir de oito anos de estudo, num único nível, redefinido como oito anos ou mais de estudo. Assim redefinido, o nível 3 de letramento mantém seu corte inferior na conclusão da $8^{a}$ série da educação fundamental, eliminando-se, porém, qualquer corte a partir daí. Ele representa a realização do mínimo estabelecido pela Constituição de 1988. Poderia, por isso, levar o nome de nível do mínimo constitucional.

Como não se poderia esperar do grupo de 10 a 14 anos que tivesse concluído o nível 3 ( $8^{\mathrm{a}}$ série do fundamental), limito aqui a análise à população de 15 anos ou mais, a qual soma cerca de 107,1 milhôes de pessoas (tabela 2). Desse total de pessoas, todas com idade para terem concluído todos os oito anos do ensino fundamental, apenas 35,8 milhões o haviam conseguido, o que corresponde a $33,4 \%$ ou a $1 / 3$ do total. Acima dessa proporção temos apenas os grupos de 20 a 24 até 40 a 44 anos, mas nunca atingindo 50\% (aliás, nem 45\%) o porcentual com ensino fundamental concluído ou com realização do minimo constitucional.

Invertendo a perspectiva de análise, defrontamo-nos ao mesmo tempo com o baixíssimo nível da educação escolar brasileira e com o 
enorme desafio colocado à educação de jovens e adultos, incompreensivelmente relegada para segundo plano. Com efeito, do total de 107,1 milhôes de brasileiros com 15 anos ou mais, temos 15,2 milhões $(14,1 \%)$ sem qualquer instrução ou com menos de 1 ano de estudo; 19,3 milhões $(18,0 \%)$ com apenas 1 a 3 anos de estudo; 36 milhões $(33,6 \%)$ com 4 a 7 anos de estudo. Acrescentem-se ainda os de número de anos de estudo ignorado, mais provavelmente situados nos níveis mais baixos de instrução. Todas essas categorias (dos sem instrução... até 4 a 7 anos de estudo) somam cerca de 71 milhões de pessoas de 15 anos ou mais, representando $66,6 \%$ ou $2 / 3$ do total, que não tiveram acesso sequer ao mínimo constitucional representado pelo ensino fundamental completo. Acrescentem-se a estes mais 9,3 milhóes de 10 a 14 anos distribuídos nas categorias "sem instrução..." e "1 a 3 anos de estudo". É importante dizer que o nível 3 de letramento como definido acima (8 anos de estudo concluídos ou mais) não representa nada mais que o mínimo constitucional. Fica a esperança de que os dados sobre anos de estudo do Censo 2000, cuja publicação está sendo aguardada para breve, permita destacar o quarto nível de letramento, que permitiria avaliar quantos conseguiram vencer pelo menos a última série do ensino médio (11 anos de estudo), completando assim o nível da educação básica, que poderia também levar o nome de minimo constitucional ampliado.

\section{Considerações finais}

Tendo como fonte os censos demográficos, concentrei a atenção, neste trabalho, em dois aspectos da problemática da educação brasileira: o analfabetismo e o que recentemente passou a ser nomeado com o termo "letramento".

Em relação ao analfabetismo, focalizei principalmente alguns aspectos: a sua emergência no final do Império como problema eminentemente político; as concepções e práticas preconceituosas e discriminatórias, tendentes à estigmatização dos analfabetos; a evolução do conceito nos censos e os problemas de comparabilidade daí resultantes; a análise das tendências de longo prazo (seculares) do analfabetismo, em números relativos e absolutos; por último, a persistência do analfabetismo no Brasil, mesmo em sua definição mais laxa, de incapacidade de ler e escrever um bilhete simples. Há fortes razões de ordem ao mesmo tempo ética e política para se denunciar qualquer tentativa de varrer para debaixo do tapete o problema do 
analfabetismo. Ainda há brasileiros - muitos milhões - marcados com o estigma do analfabetismo, essa forma extrema de exclusão educacional, geralmente secundada por outras formas de exclusão social.

O experimento de classificação da população em níveis de letramento revelou, com toda a crueza, a situação do país no ano 2000: entre a população de 15 anos ou mais, apenas $1 / 3$ havia atingido o nível 3 de letramento, que não significa nada mais que o minimo constitucional (8 anos ou mais de estudo concluídos ou o fundamental completo). Os outros $2 / 3$ da população de 15 anos ou mais (cerca de 71 milhões), compreendendo desde os "sem instrução e menos de 1 ano de estudo" até os distribuídos em todas as categorias de 1 a 7 anos de estudo, dizem muito bem do tamanho do desafio posto à educação nos próximos anos (ou décadas?). E nem se aprofundou a questão da "progressiva universalização do ensino médio gratuito" determinada pela Constituição de 1988 em seu art. 208, II (Brasil, 1997).

Em termos de política educacional, os resultados do estudo obrigam a questionar fortemente o princípio e a prática de, a título de priorização da educação fundamental na "idade própria", relegar-se a segundo plano a educação de jovens e adultos e a educação infantil. De um lado, é preciso enfatizar que o direito do jovem e do adulto à educação fundamental não é em nada menor que o direito da criança e do adolescente à mesma educação em "idade própria". De outro, o não-acesso de muitas crianças ainda à educação infantil está constituindo-se rapidamente em novo fator de diferenciação e discriminação no processo de escolarização.

Por último, parece-me que a área da educação poderia dar mais atenção às potencialidades, aos limites e aos métodos relacionados com o uso dos dados originados de fontes como os censos, as PNADs e os registros escolares. Temo que, com o argumento de livrar-se do quantitativismo e dos problemas relacionados com a utilização das estatísticas educacionais, tenha-se acabado por jogar fora a criança junto com a água do banho. Se assim foi, talvez se possa ainda recuperá-la...

\section{Recebido e aprovado em outubro de 2002.}

\section{Notas}

1. Falando do poder denunciador das boas estatísticas sociais, Marx deixa também entrever as razões de ordem político-ideológica que podem levar governos e parlamentos a manipular a produção das estatísticas: "Ficaríamos horrorizados ante a nossa própria situação 
caso nossos governos e parlamentos constituíssem, periodicamente, como na Inglaterra, comissōes de inquérito acerca das condiçôes econômicas; caso essas comissōes fossem investidas, a exemplo da Inglaterra, da mesma plenitude de poderes para pesquisar a verdade; caso fosse possível encontrar, para tal missão, homens tão especializados, imparciais e intimoratos quanto o são os inspetores de fábrica na Inglaterra e os seus relatores médicos sobre Public Health (Saúde Pública), os seus comissários encarregados de examinar a exploração das mulheres e crianças, as condições de moradia e alimentação etc. Perseu precisava de um capacete da invisibilidade para perseguir os monstros. Nós puxamos o capacete mágico a fundo sobre os nossos olhos e orelhas, para podermos negar a existência de monstros" (Marx, 1983, v. I, t. I, p. 12).

2. Retomam-se aqui alguns aspectos do artigo "Utilização das estatísticas educacionais dos censos demográficos e dos registros escolares: uma tipologia de análises" (Ferrari, 1979, p. 254 ss.).

3. Sobre o que se disse até aqui, nesta parte, veja-se principalmente as obras de: R. Pressat, L'analyse démographique ( $A$ análise demográfica), 1961, parte 1, capítulo 1; Nations Unies, Dictionnaire demographique multilangue (Dicionário demográfico multilíngüe), 1958; A. Landry, Traité de démographie (Tratado de demografia), 1949, capítulos 3 e 4. $\mathrm{O}$ que esses autores denominam análise do estado ou da estrutura da população, W. S. Thompson, em Population Problems (Problemas populacionais), 1953, denomina composição (composition) da população.

4. Ver BRASIL. Ministério da Agricultura, Indústria e Comércio. Diretoria-Geral de Estatística. Recenseamento Geral do Brasil 1920, v. IV, parte $4^{\mathrm{a}}$ - População. Ver também Ferrari (1985).

\section{Referências bibliográficas}

BRASIL. Ministério da Agricultura, Indústria e Comércio. Diretoria Geral de Estatística. Recenseamento Geral do Brasil: 1920. Rio de Janeiro, 1920. v. 4, pt.4: população.

BRASIL. Constituição (1988). Constituiçãa da República Federativa do Brasil. 17. ed. São Paulo: Saraiva, 1997.

CARNEIRO, L. Voto dos analfabetos. Petrópolis: Vozes, 1964.

CARVALHO, J. C. B.; KAPPEL, M. D. B.; ALVES, M. I. C. Condições educacionais. In: IBGE. Indicadores sociais: uma análise da década de 1980. Rio de Janeiro: IBGE, 1995. p. 283-296.

CIPOLLA, C. Educación y desarrollo en Occidente. Barcelona: Ariel, 1970.

CRUZ, O. L. As estatísticas educacionais: uma tentativa de esclarecimento. Rio de Janeiro: IBGE/DPE/DEISO, [1988?]. 22 p. (datil.)

DAGLISH, C. Literacy and the offender. Adult Education, London, v. 56, n. 1, p. 23-26, jun. 1983.

Educ. Soc., Campinas, vol. 23, n. 81, p. 21-47, dez. 2002

Disponível em <http://www.cedes.unicamp.br> 
FERNANDES, F. Dicionário de sinônimos e antônimos da língua portuguesa. 11. ed. Porto Alegre: Globo, 1957.

FERRARO (FERRARI), A. R. Utilização das estatísticas educacionais dos censos demográficos e dos registros escolares: uma tipologia de análises. Educação \& Realidade, Porto Alegre, v. 4, n. 2, p. 253-266, jul./set. 1979.

FERRARO (FERRARI), A. R. Analfabetismo no Brasil: tendência secular e avanços recentes; resultados preliminares. Cadernos de Pesquisa, São Paulo, n. 52, p. 35-49, fev. 1985.

FERRARO (FERRARI), A. R. Escola e produção do analfabetismo. Educação \& Realidade, Porto Alegre, v. 12, n. 2, p. 81-96, jul./dez. 1987.

FERRARO (FERRARI), A. R. Alfabetização e escolarização de crianças $e$ adolescentes no Brasil: um diagnóstico. Porto Alegre, $1999^{\mathrm{a} .} 70$ p. (Relatório de pesquisa, CNPq)

FERRARO (FERRARI), A. R. Alfabetizar é escolarizar. Sociedade \& Estado, Brasília, v. 24, n. 2, p. 323-348, jul./dez. 1999 b.

FLETCHER, P. R. A repetência no ensino de $1^{\circ}$ grau: um problema negligenciado da educação brasileira: uma análise preliminar e sugestão de avaliação adicional. Revista Brasileira de Administração da Educação, Porto Alegre, v. 3, n. 1, p. 10-41, jan./jun. 1985.

FLETCHER, P. R. e RIBEIRO, S. C. A educação na estatística nacional. Trabalho apresentado no Seminário de Avaliação das PNADs de 1980, АвеP, Nova Friburgo, 13-15 jun.1988. 19 p. e anexos 1 e 2.

FREIRE, P. Ação cultural para a prática da liberdade e outros escritos. 9. ed. São Paulo: Paz e Terra, 2001.

GOODY, J. A lógica da escrita e a organização da sociedade. Lisboa: Edições 70, 1987.

INSTITUTO BRASILEIRO DE GEOGRAFIA E ESTATÍSTICA. Censo Demográfico: 1940, 1950, 1960, 1970, 1980, 1991.

INSTITUTO BRASILEIRO DE GEOGRAFIA E ESTATISTICA. Conselho Nacional de Estatística. Contribuições para o estudo da demografia no Brasil. Rio de Janeiro: IBGE/CNE, 1961. p. 392-400. 
INSTITUTO BRASILEIRO DE GEOGRAFIA E ESTATISTICA. Contagem da População 1996. (CD)

INSTITUTO BRASILEIRO DE GEOGRAFIA E ESTATISTICA. Censo demográfico 2000. Brasília, DF.: IBGE, 2001. (CD)

LANDRY, A. Traité de Demographie. 2e éd. rev. et compl. Paris: Payot, 1949.

LlOMOVATTE, S. Analfabetismo en Argentina. Buenos Aires: Niño y Dávila, 1989. 57p.

LOURENÇO FILHO. Estatística e educação. Revista Brasileira de Estatística, Rio de Janeiro, v. 1, n. 1, p. 66-85, jan./mar. 1940.

MARX, K. O capital. São Paulo: Abril Cultural, 1983. v.1.

NATIONS UNIES. Dictionnaire démographique multilangue. New York: Nations Unies, 1958.

PAIVA, V. Um século de educação republicana. Pró-Posições, Campinas, v. 1, n. 2, p. 7-21, jul. 1990.

PERROTTA, C. O conceito de alfabetização: aspecto histórico. Tecnologia Educacional, Rio de Janeiro, v. 14, n. 62, p. 6-11, jan./ fev. 1985.

PRESSAT, R. L'analyse démographique: méthodes - résultats applications. Paris: PUF, 1961.

RODRIGUES, R. C. O voto do analfabeto face às constituiçôes republicanas do Brasil. Brasília, DF: Senado Federal, 1965.

SOARES, M. Letramento: um tema em três gêneros. Belo Horizonte: Autêntica, 1998.

TFOUNI, L. V. Adultos alfabetizados: o avesso do avesso. Campinas: Pontes, 1988.

THOMPSON, W. S. Population problems. 4. ed. New York: McGrawHill, 1953. 